IRA-International Journal of Applied Sciences ISSN 2455-4499; Vol.06, Issue 02 (2017)

Institute of Research Advances

Pg. no. 41-54

https://research-advances.org/index.php/IRAJAS

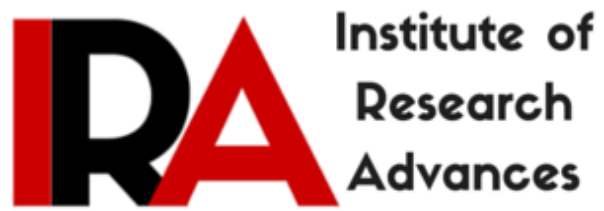

\title{
Morphological Identification of Horse Flies (Diptera: Tabanidae) and Estimation of their Seasonal Abundance in Al-Showak District, Gedaref State, Eastern Sudan
}

\author{
Hamid I. M. N. Croof ${ }^{1}$ Mai M. Nour ${ }^{2}$ Nahla O. M. Ali ${ }^{3}$ \\ ${ }^{1}$ Ministry of Animals Resources, Gedaref State, Gedaref, Sudan. \\ ${ }^{2}$ Department of Biology and Environmental studies, Faculty of Science and Technology, \\ El Neelain University, Khartoum, P.O. Box: 12702, Sudan. \\ ${ }^{3}$ Department of Parasitology, Faculty of Veterinary Medicine, University of Khartoum, P. \\ O. Box 32 Shambat Campus, Khartoum North 13314, Sudan.
}

Type of Review: Peer Reviewed.

DOI: http://dx.doi.org/10.21013/jas.v6.n2.p3

\section{How to cite this paper:}

Croof, H., Nour, M., \& Ali, N. (2017). Morphological Identification of Horse Flies (Diptera: Tabanidae) and Estimation of their Seasonal Abundance in Al-Showak District, Gedaref State, Eastern Sudan. IRA-International Journal of Applied Sciences (ISSN 2455-4499), 6(2), 41-54. doi:http://dx.doi.org/10.21013/jas.v6.n2.p3

(C) Institute of Research Advances

\section{(cc) BY-NC}

This work is licensed under a Creative Commons Attribution-Non Commercial 4.0 International License subject to proper citation to the publication source of the work.

Disclaimer: The scholarly papers as reviewed and published by the Institute of Research Advances (IRA) are the views and opinions of their respective authors and are not the views or opinions of the IRA. The IRA disclaims of any harm or loss caused due to the published content to any party. 


\section{ABSTRACT}

The aim of this study was to identify the tabanid flies in the Gedaref State, Eastern Sudan and to estimate their seasonal abundance. A number of 374 flies sample were collected by the trapping method in the period October 2014 to October 2015 and were sorted out using certain morphological features that include; size, head, thorax, wings, legs, antennae and abdomen. The observed features of 47 randomly selected samples were recorded and were used to create an identification key that can be used for future characterization and identification of any member of the Tabanidae family. More tabanids flies were collected during the wet (52.29\%) than the dry season (47.71\%). A number of 5 species of Tabanidae namely; Tabanus autumnalis (Szilády 1914); Tabanus leleani (Austen 1920); Atylotus pulchellus (Loew 1858); Hybomitra mendica (Villeneuve 1912) and Philoliche sp. were reported for the first time in the state of Gedaref. The method described here has advantages over the other methods of identification; that it is simple, costless, and requires no skillful person to perform. The collection procedure is very crucial, for the specimen must be of high-quality. This key will facilitate the recognition of the vector species and its possible role in the transmission of the parasitic and/or viral animals' diseases in the area.

Keywords: Abundance, Al-Showak, Gedaref, Identification, Morphology, Sudan, Tabanids

\section{INTRODUCTION}

Tabanids are present on every continent except Antarctica and the diversity within the family is greatest in the tropics [1]. The Tabanidae are true flies and members of the insect order Diptera [2], [3] with the families Athericidae, Pelecorhtnchidae and Oredeptidae, Tabanidae are classified in the super family Tabanoidea. Along with Rhagionoidea, this superfamily makes up the infraorder Tabanomorpha. Tabanoid families seem to be united by the presence of a venom canal in the mandible of the larvae. The family Tabanidae includes approximately 4300 to 4500 species and subspecies worldwide. Of these, 335 species in 25 genera are found in the Nearctic Region [4], over 1,300 of the genus Tabanus [5]. The family Tabanidae is divided into three subfamilies: Chrysopinae, Tabaninae and Pangoniinae [6], [7]. The former two of these subfamilies contain most of the economically important tabanids. Tabanids in the subfamily Chrysopinae are called deer flies, with nearly all being members of the genus Chrysops. The subfamily Tabaninae includes horse flies, represented by the genera Tabanus and Hybomitra.

Tabanid adults are stout-bodied flies and can be distinguished as horse flies or deer flies based on several morphological characteristics. The antennae are prominent and extent anteriorly. In general, they possess a fairly large size, striking appearance and diurnal habits. The eyes of many species are brilliantly patterned with shades of green, yellow, orange, and violet. They often consist of large ommatidial facets dorsally and smaller facets ventrally [1].

Females of most Tabanidae species attack mammals, principally Equidae, Bovidae, Camelidae and humans. Many tabanids are selective in attacking specific body regions of their hosts, regardless of colour. Like other blood-sucking flies, tabanids have a negative economic effect on milk production where they commonly live [2]. Moreover, tabanids are known worldwide as important mechanical vectors of virus, bacteria, protozoans and helminthes, which cause diseases in some wild and domestic animals [8], [9], [10], [11], [12]. The transmission of these pathogens occurs by tabanid species of the genera Tabanus, Haematopota and Chrysops. In addition to, tabanids have veterinary importance as they represent significant pests of livestock, causing reductions in weight gain, milk yield and feed-utilization efficiencies, due to their painful, continuous biting behavior. The blood meal size in females varies from 20-25 mg for many Chrysops species to almost $700 \mathrm{mg}$ for Tabanus atratus [1]. 
Tabanids are attracted to a variety of visual cues including color and shape [13] where as contrasting colors play an important role in tabanid attraction to two-dimensional panels, these flies appear to be more attracted to dark 3-dimensional objects [14], [15]. Synthetic attractants in traps are also used in many part of the world to collect female tabanids [16]. Efficacy of tabanid traps is mainly increased by the addition of chemicals that mimic natural host odors [17]. Besides these synthetic attractants, some natural attractants such as the old urine of cows or African buffalo, horses, and rhinoceros are known mainly for tsetse species (Glossinidae) and Tabanidae [18], [19], [20], [21].

Tabanids control is difficult since in a given area multiple species do exist with different seasonal occurrences and biological characteristics. Moreover, the host contact time is very short "4 min" every 34 days. Hence, the spatial and temporal recognition of the species composition of tabanids is very crucial when considering the vector control strategy. Therefore, the objectives of this work are to identify morphologically the tabanids species, to provide a simple identification key, and to estimate their seasonal abundance in Al-Showak district in Gedaref state, Eastern Sudan.

\section{MATERIALS \& METHODS}

\subsection{Study Area}

This study is carried out in Al-Showak district in Gedaref state, Eastern Sudan (Latitude: $14^{\circ} 25^{\prime} 27.61^{\prime \prime}$; longitude: $35^{\circ}$ 52'36.35"E and altitude: $1682 \mathrm{ft}$ ), which lies in the savannah region of Sudan. The geographical feature is marked by a group of hills surrounding it and small "khors" (tiny dry valley creeks). The climate is a tropical continental one with a rainy season that extends four months (June October), with an average of annual rainfall of 700 to $900 \mathrm{~mm}$, and a dry season (November - May) with an average min-max temperature of $34-40^{\circ} \mathrm{C}$. In the autumn, large pools of water and green pastures with trees of various kinds of Acacia cover the area. Gedaref State is characterized with rich vegetation, especially during the rainy season. The main trees and bushes found in the study area are Balanites aegyptiaca, Acacia seyal, Acacia mellifera,Acacia nilotica, Acacia Senegal, Azadirachta indica and Ziziphus spina-christi [22].

\subsection{Samples Collection}

A total of 374 samples of tabanids flies were collected by the trapping method during the period October 2014 to October 2015. In this study, tabanids were caught by using two types of blue / black clothes (Nettings), NZ1 traps and H-trap and two types of natural attractive odour, urine and stool of camel were placed as attractive odour for the tabanid flies. The traps were installed near camels herd to collect the flies. The collected flies were kept in $96 \%$ ethyl alcohol and were stored at $4^{0} \mathrm{C}$ till to be used. In the laboratory, the captured flies were sorted by separating the tabanids from the other Diptera.

\subsection{Morphological identification of field collected Tabanid Flies}

During this study certain identification criteria were used which include: Body length - Head - Antennae Wing - Thorax - Leg (hind) - Face \& frons - Abdomen. A total number of 47 tabanid samples were selected randomly from October 2014 collections and were used for morphologic and / or morphometric analysis on June 2015. The investigated 38 features are illustrated in Table 1. 
Table 1: Morphologic Features used in Identification of Tabanids in this study.

\begin{tabular}{|c|c|c|}
\hline Number & Feature & Characteristics \\
\hline 1 & Body length & $\begin{array}{l}\text { Body length in }\left(\partial^{\lambda}\right):(-)=\text { shorter than } 17 \mathrm{~mm},(+)=\text { longer than } 17 \\
\mathrm{~mm}\end{array}$ \\
\hline 2 & Ocelli & Ocelli: $(-)=$ absent,$(+)=$ present. \\
\hline 3 & Eyes (4) & Eyes: $(-)=$ bare,$(+)=$ hairy. \\
\hline 4 & Antennae & $\begin{array}{l}\text { Length of antennae: }(-)=\text { less than or nearly equal to } 3 / 4 \text { length of } \\
\text { head, }(+)=\text { more than } 3 / 4 \text { length of head. }\end{array}$ \\
\hline 5 & Antennal & Antennal pedicel: $(-)=$ elongated slender, $(+)=$ cup shape \\
\hline 6 & Antennal & $\begin{array}{l}\text { Antennal pedicel reddish yellow to reddish or yellowish brown color: } \\
\qquad(-)=\text { absent, }(+)=\text { present. }\end{array}$ \\
\hline 7 & Antennal & $\begin{array}{l}\text { Antennal pedicel dark reddish brown to blackish color: }(-)=\text { absent, } \\
\qquad(+)=\text { present. }\end{array}$ \\
\hline 8 & Antennal & Antennal pedicel black color: $(-)=$ absent,$(+)=$ present \\
\hline 9 & Antennal & $\begin{array}{l}\text { Antennal scape, pedicel \& basal flagellomere orange color: }(-)= \\
\text { absent, }(+)=\text { present. }\end{array}$ \\
\hline 10 & $\begin{array}{c}\text { Basal } \\
\text { flagellomere }\end{array}$ & Basal flagellomere dark brown color: $(-)=$ absent,$(+)=$ present. \\
\hline 11 & $\begin{array}{c}\text { Basal } \\
\text { flagellomere }\end{array}$ & $\begin{array}{l}\text { Basal flagellomere reddish yellow to reddish or yellowish brown } \\
\text { color: }(-)=\text { absent, }(+)=\text { present. }\end{array}$ \\
\hline 12 & $\begin{array}{c}\text { Basal } \\
\text { flagellomere }\end{array}$ & Basal flagellomere black color: $(-)=$ absent, $(+)=$ present. \\
\hline 13 & body color & $\begin{array}{l}\text { Color of style with the same color of basal antennal segments: }(-)= \\
\text { absent, }(+)\end{array}$ \\
\hline 14 & body color & Color of style reddish yellow: $(-)=$ absent,$(+)=$ present. \\
\hline 15 & body color & Color of style dark brown: $(-)=$ absent,$(+)=$ present. \\
\hline 16 & body color & Color of style black: $(-)=$ absent, $(+)=$ present \\
\hline 17 & subcallus & Subcallus swollen: $(-)=$ absent,$(+)=$ present \\
\hline 18 & subcallus & Subcallus entirely bare $\&$ shining: $(-)=$ absent,$(+)=$ present \\
\hline 19 & subcallus & Subcallus entirely bare $\&$ shining: $(-)=$ absent,$(+)=$ present \\
\hline 20 & subcallus & $\begin{array}{l}\text { Subcallus more or less shining on the upper part only: }(-)=\text { absent, } \\
\qquad(+)=\text { present }\end{array}$ \\
\hline 21 & Thorax & Thorax: $(-)=$ not striped,$(+)=$ striped. \\
\hline 22 & Thorax & Thorax with 3 stripes: $(-)=$ absent,$(+)=$ present. \\
\hline 23 & Thorax & Thorax with 4 stripes: $(-)=$ absent,$(+)=$ present \\
\hline 24 & Thorax & Thorax with 5 stripes: $(-)=$ absent,$(+)=$ present \\
\hline 25 & Legs & Hind tibia: $(-)=$ without apical spin,$(+)=$ with apical spin \\
\hline 26 & wing & Wing: $(-)=$ not maculated,$(+)=$ maculated \\
\hline 27 & wing & $\begin{array}{c}\text { Maculated wing: }(-)=\text { partially covered with maculae, }(+)= \\
\text { completely covered with maculae. }\end{array}$ \\
\hline 28 & wing & Wing with rosettes-shape: $(-)=$ present,$(+)=$ absent \\
\hline 29 & wing & Wing veins yellow color: $(-)=$ absent,$(+)=$ present . \\
\hline
\end{tabular}




\begin{tabular}{|c|c|c|}
\hline 30 & wing & $\begin{array}{l}\text { Wing veins dark brownish to blackish color: }(-)=\text { absent, }(+)= \\
\text { present. }\end{array}$ \\
\hline 31 & wing & $\begin{array}{l}\text { Wing veins yellowish on basal half and brownish on apical half: }(-)= \\
\text { absent, }(+)=\text { present. }\end{array}$ \\
\hline 32 & Abdomen & Abdomen: $(-)=$ without patterns,$(+)=$ with patterns \\
\hline 33 & Abdomen & $\begin{array}{l}\text { Abdomen orange yellow color with blackish median longitudinal } \\
\text { stripe: }(-)=\text { absent, }(+)=\text { present. }\end{array}$ \\
\hline 34 & Abdomen & $\begin{array}{l}\text { Abdomen whitish or grayish color with } 4 \text { dark longitudinal stripes: (- } \\
\qquad)=\text { absent },(+)=\text { present. }\end{array}$ \\
\hline 35 & Abdomen & $\begin{array}{c}\text { Abdomen reddish brown color: }(-)=\text { with broad blackish median } \\
\text { stripe \& } 2 \text { lateral narrow blackish stripes, }(+)=\text { with triangles greyish } \\
\text { median stripe \& } 2 \text { oval greyish sublateral stripes. }\end{array}$ \\
\hline 36 & Abdomen & $\begin{array}{l}\text { Abdomen olive grey with } 3 \text { greyish longitudinal stripes: }(-)=\text { absent, } \\
\qquad(+)=\text { present }\end{array}$ \\
\hline 37 & Abdomen & $\begin{array}{l}\text { Abdomen olive grey with } 3 \text { greyish longitudinal stripes: }(-)=\text { absent, } \\
\qquad(+)=\text { present }\end{array}$ \\
\hline 38 & Abdomen & $\begin{array}{l}\text { Abdomen blackish color: }(-)=\text { with } 2 \text { yellow triangular spots on terga } \\
\qquad 3 \& 4,(+)=\text { with } 3 \text { greyish longitudinal stripes. }\end{array}$ \\
\hline
\end{tabular}

Continued Table 1: Morphologic Features used in Identification of Tabanids in this study.

\section{RESULTS}

A total of 39 adult morphological characters with 78 character states were examined in all of the 47 flies samples. The Characters include both qualitative and quantitative type characters to increase the certainty of the results. The obtained results are summarized in Table 2.

Certain morphological characteristics were used to differentiate adult horse and deer flies as described previously [1]. All tabanids collected in this study have large stout body with a large head bean shaped and broader than long. They have well developed eye (diurnal activity). Concerning the body length; when it is $10-30 \mathrm{~mm}$, then it is classified as Tabanus species, and if it is $6-11 \mathrm{~mm}$, then it is classified as Chrysops species. If the sample has no ocelli it is classified as Tabanus species. The eye is unicolorous or might be horizontally banded as the color is disappeared after the death of the fly. As shown in Table 2 some samples have ocelli and others are lacking. Overall, 31.9\% of the collected samples have ocelli.

According to the number of flagellum segments, all the collected samples have 5 segments with enlarged flagellum base. The presence of this feature in these samples classifies them as Tabanus spp. This is well illustrated in Plates 1 - 3. However, is sample Sh-T38 as illustrated in Plate 4 lacks this enlargement. Sample Sh-T38 also has 8 segments, and an elongated type of mouthparts (Plate 5). These two features place sample Sh-T38 in the subfamily Pangoniinae and it is Pangonia spp. Nearly all of the collected tabanids have large and prominent sucking-lapping type of mouthparts (Data not shown), projecting downward and forward in front of the head. The blood feeding female horse fly is equipped with bladelike mouthparts, which cut tissues and blood vessels and cause blood to flow to wounds. Females then use their sponge-like mouthparts for sucking up blood. Males only feed on pollen and nectar and have similar, but much weaker mouthparts. 
There are 4 distinct forms of antennae observed in the collected samples. Type I where the color of the entire antenna is light and the size is small and the flagellum is consisted of 5 segments; this is exemplified by sample Sh-T17 in Plate 1. Type II the color of the entire antenna is light and the size is large and the flagellum is consisted of 5 segments; this is exemplified by sample Sh-T46 in Plate 2. Type III where the color of the entire antenna is dark and the size is large and the flagellum is consisted of 5 segments; this is exemplified by sample Sh-T40 in Plate 3. Type IV where the color of the entire antenna is dark and the size is small and the flagellum is consisted of 8 segments and this is exemplified by sample Sh-T38 in Plate 4.

All the collected samples have stout legs that end in 3 pads ( 2 pulvilli and 1 Empodium). There is no apical spine in the hind tibia in most of the collected sample as exemplified by sample Sh-T23 in Plate 6 which also has large white areas and the end is dark brown. While few samples have apical spine in the hind tibia and the end is pale as exemplified by sample Sh-T37 in Plate 7.

A typical wing structure of Tabanid flies of genus Tabanus was identified in the collected samples, which showing different parts such as basicosta (b) at the base of costa (C), below costa lies sub-costa (Sc), costa and subcostal are joined by humeral cross vein (h), light brownish pterostigma (Ptstg), R1 - anterior branch of radius, $\mathrm{R} 2+3$ (R2 and $\mathrm{R} 3$ fused in Tabanidae), R4, R5- posterior branches of radius, medial veins M1, M2, M3 originating from discal cell (DC), M4 originating from medial-cubital vein (m-cu), 5 posterior cells PC1, PC2, PC3, PC4 and PC5 are present, 1A and 2A are branches of anal veins, first cubital (Cu1) and 1st anal cell (1A) fused apically to form $\mathrm{Cu} 1+1 \mathrm{~A}$, first basal cell (bc1) and second basal cell (bc2) are present just above discal cell, radial medial vein ( $\mathrm{r}-\mathrm{m})$ present behind first basal cell as illustrated in Plates $8-11$.

The wing of all the collected samples has a length of $6-30 \mathrm{~mm}$ with a well developed venation. Most of them have similar venation with hexagonal discal cell located more or less in the centre. The R4 and R5 veins are straddling the apex of the wing. As previously described [23], these R4 and R5 are bifurcated and ending at opposite to each other apically, characteristic to most brachycera. The extension of vein R4 sometimes present and called as appendix. However, there are 4 different form of wings recognized in the collected samples: Type I which is identical to the shape reported for Tabanus and is exemplified by sample Sh-T13 in Plate 8. Type II which is identical to the structure known for Chrysops and is exemplified by sample Sh-T37 in Plate 9. Type III which is identical to the shape reported for Haematopota and is exemplified by sample Sh-T44 in Plate 10. Type IV which is identical to the shape reported for Pangonia in which R4 vein has appendix and is exemplified by sample Sh-T38 in Plate 11.

A number of 156 Tabanids flies were caught during dry season (March - June), 148 (94.87\%) were females and $8(5.13 \%)$ were males. While in wet season (July, August, October and December) 171 sample of flies were collected. $131(76.61 \%)$ were females and 40 (23.39\%) were males as shown in Table 2.

Table 11: Density Variation of Tabanids flies according to the season of collection during this study.

\begin{tabular}{|c|c|c|c|c|c|c|}
\hline \multirow[b]{2}{*}{ Season of collection } & \multicolumn{2}{|l|}{ Female Tabanids } & \multicolumn{2}{|l|}{ Male Tabanids } & \multicolumn{2}{|l|}{ Total } \\
\hline & Collected number & $\%$ & Collected number & $\%$ & Collected number & $\%$ \\
\hline Dry & 148 & 94.87 & 8 & 5.13 & 156 & 47.71 \\
\hline Wet & 131 & 76.61 & 40 & 23.39 & 171 & 52.29 \\
\hline Total & 279 & 85.32 & 48 & 14.68 & 327 & 100 \\
\hline
\end{tabular}


IRA-International Journal of Applied Sciences

Table 2: Morphological features observed and used in the identification of Tabanids flies collected during this study. Empty cell means that this feature was not analyzed in the sample.

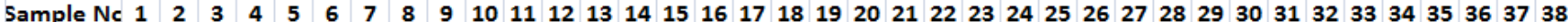

\begin{tabular}{|c|c|c|c|c|c|c|c|c|c|c|c|c|c|c|c|c|c|c|c|c|c|c|c|c|c|c|c|c|c|c|c|c|c|c|c|c|c|}
\hline & & & & & & & & & & & & & & & & & & & & & & & & & & & & & & & & & & & & & \\
\hline & & & & & & & & & & & & & & & & & & & & & & & & & & & & & & & & & & & & & \\
\hline 2 & + & + & & & & & & & & & & & & & & & & & & & & & & & & & & & & & & & & & & & \\
\hline 3 & - & + & & & & & & & & & & & & & & & & & & & & & & & & & & & & & & & & & & & \\
\hline 4 & - & + & & & & & & & & & & & & & & & & & & & & & & & & & & & & & & & & & & & \\
\hline 5 & - & + & & & & & & & & & & & & & & & & & & & & & & & & & & & & & & & & & & & \\
\hline 6 & - & + & & & & & & & & & & & & & & & & & & & & & & & & & & & & & & & & & & & \\
\hline 7 & - & - & + & - & + & + & - & - & + & + & - & - & - & - & + & - & - & + & - & - & + & - & + & - & + & + & + & & - & - & + & + & - & & - & & \\
\hline 8 & - & + & - & - & - & + & - & - & + & + & - & - & - & - & + & - & - & - & + & - & + & - & + & - & + & + & + & + & + & - & + & + & - & - & - & & \\
\hline 9 & - & - & - & - & + & + & - & - & - & + & - & - & - & - & + & - & - & - & - & + & + & + & - & - & + & + & - & + & - & - & + & + & - & - & - & & \\
\hline 10 & - & - & - & - & - & - & - & + & - & + & - & - & + & - & + & - & - & - & - & + & + & - & - & + & - & + & - & + & - & + & + & - & + & - & - & & \\
\hline 11 & + & - & - & + & - & - & - & + & - & - & - & + & - & - & - & + & + & + & - & - & + & - & + & - & + & + & + & + & + & - & + & + & - & - & - & & \\
\hline 12 & - & - & + & - & - & + & - & - & + & - & + & - & + & - & + & - & + & - & + & - & + & - & - & - & + & + & + & + & + & $=$ & + & + & - & - & - & & \\
\hline 13 & + & - & + & - & + & - & - & + & - & - & - & - & + & - & + & - & + & - & - & + & + & - & + & - & + & + & - & + & - & + & + & + & - & - & - & & \\
\hline 14 & - & - & + & + & + & + & - & - & + & - & - & - & + & + & - & - & - & - & + & - & + & - & + & - & + & + & - & + & - & + & + & + & - & - & - & & \\
\hline 15 & - & - & - & + & + & + & - & - & - & - & + & - & - & - & + & - & - & - & - & + & + & + & - & - & + & + & + & + & - & + & + & + & - & - & - & & \\
\hline 16 & - & - & + & + & - & + & - & - & - & - & - & + & - & - & + & - & - & - & + & - & + & + & - & - & + & + & + & + & + & - & + & + & - & & + & & \\
\hline 17 & - & - & + & - & - & + & - & - & + & - & - & - & - & - & + & - & - & - & + & - & + & + & - & - & + & + & + & + & + & + & + & + & - & - & - & & \\
\hline 18 & - & - & + & - & - & - & + & + & - & + & - & + & - & - & - & + & - & - & - & + & - & - & - & - & + & + & + & + & + & + & + & + & - & - & - & & \\
\hline 19 & - & - & - & + & - & - & - & - & - & - & - & - & - & - & + & - & - & - & + & - & - & - & - & - & + & + & + & + & + & + & + & + & - & - & + & & \\
\hline 20 & - & - & + & - & + & + & - & - & - & - & - & - & + & - & - & - & - & - & + & - & + & + & - & - & + & + & + & + & + & + & + & + & - & - & - & & \\
\hline 21 & - & - & + & - & + & + & - & - & - & - & + & + & + & - & - & - & - & - & + & - & + & + & - & - & + & + & + & + & + & + & + & + & - & - & - & & \\
\hline 22 & - & - & + & - & - & + & - & - & - & - & + & - & - & - & + & - & - & - & + & - & + & + & - & - & + & + & + & & + & + & + & + & - & - & - & - & \\
\hline 23 & - & - & - & + & - & + & - & - & - & - & + & - & - & - & - & + & - & - & + & - & + & + & - & - & + & + & + & + & - & + & + & + & - & - & - & + & \\
\hline 24 & - & - & + & + & - & + & - & - & - & - & + & - & - & - & + & - & + & - & + & - & + & + & -1 & - & + & + & + & + & + & - & + & + & - & - & - & & \\
\hline 25 & - & + & + & + & - & + & - & - & - & - & + & - & + & - & - & - & - & - & + & - & + & - & + & - & + & + & + & + & + & - & + & + & - & - & - & - & \\
\hline 26 & - & - & + & + & + & + & - & - & - & - & + & - & - & - & + & - & - & + & - & - & + & - & + & - & + & + & + & + & + & - & + & + & - & + & $=$ & & \\
\hline 27 & - & - & - & - & - & - & - & - & - & - & + & - & - & - & + & - & - & - & + & - - & - & - & - & - & + & + & + & + & + & - & + & + & + & - & - & & \\
\hline 28 & - & + & + & - & + & + & - & - & - & - & + & - & - & - & + & - & + & - & - & + & + & + & - & - & + & + & + & + & - & + & + & + & - & - & + & . & \\
\hline 29 & - & - & - & + & - & + & - & - & - & - & + & - & - & - & + & - & - & - & + & - & + & + & - & - & + & + & + & + & - & - & + & + & - & - & + & . & \\
\hline 30 & - & - & - & - & + & - & + & - & - & + & - & - & - & - & + & - & - & - & + & - & + & + & - & -1 & + & + & + & + & + & - & + & + & - & - & + & 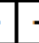 & \\
\hline 31 & - & - & + & - & + & + & - & - & - & - & + & - & - & + & - & - & -1 & - & + & - & + & + & -1 & - & + & + & + & + & + & - & + & + & - & - & + & & \\
\hline 32 & - & - & + & + & - & + & - & - & - & + & - & - & - & - & + & - & - & + & - & - & + & + & -1 & - & + & + & + & + & + & - & + & + & - & - & - & 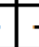 & \\
\hline 33 & - & + & - & - & + & + & - & - & - & + & + & - & - & - & + & - & + & - & + & - & + & + & - & - & - & - & - & - & + & - & + & - & - & - & + & & \\
\hline 34 & - & + & + & - & - & + & - & - & - & + & + & - & - & - & - & + & - & + & - & - & + & + & - & - & + & + & - & - & - & - & + & + & - & - & - & . & \\
\hline 35 & - & - & - & + & - & + & - & - & - & + & + & - & - & - & - & + & - & + & - & - & + & + & -1 & - & + & + & + & + & - & - & + & + & - & - & - & 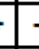 & \\
\hline 36 & - & - & + & + & - & + & - & - & - & + & + & - & - & - & + & - & - & - & + & - & + & + & - & - & + & + & + & + & + & - & + & + & - & - & - & & \\
\hline 37 & - & - & + & - & - & + & - & - & - & + & + & - & - & - & + & - & - & - & + & - & + & + & -1 & - & + & + & + & + & + & - & + & + & - & - & - & 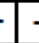 & \\
\hline 38 & - & + & + & - & + & + & - & - & - & - & + & - & + & - & - & - & + & + & - & - - & + & + & -1 & - & + & + & + & + & - & + & + & - & - & - & - & & \\
\hline 39 & + & + & + & - & + & + & - & - & - & - & + & - & - & + & - & - & + & + & - & - & + & - & + & - & + & + & + & + & - & + & + & - & - & - & - & - & \\
\hline 40 & - & - & - & - & - & + & - & - & - & - & + & + & - & - & - & + & - & + & - & - & + & + & - & - & + & + & + & + & - & - & + & - & - & - & - & + & \\
\hline 41 & - & + & + & + & + & + & - & - & - & - & + & - & - & + & - & - & - & + & - & - & + & -1 & -1 & + & + & + & + & + & - & - & + & + & - & - & - & + & \\
\hline 42 & - & - & - & - & - & + & + & - & - & + & - & + & + & - & - & + & - & - & + & - & + & + & - & - & + & + & + & + & - & + & - & - & - & - & - & + & \\
\hline 43 & - & - & - & - & - & + & + & - & - & + & - & + & + & - & - & + & - & - & + & - & + & + & - & - & + & + & + & + & - & + & - & - & - & - & - & & \\
\hline 44 & - & - & - & - & - & + & + & - & - & + & - & + & + & - & - & + & - & - & + & - & + & + & - & - & + & + & + & + & - & + & - & - & - & - & - & 7 & \\
\hline 45 & - & - & - & - & - & + & + & - & - & + & - & + & + & - & - & + & - & - & + & - & + & + & - & - & + & + & + & + & - & + & - & - & - & - & - & & \\
\hline 46 & - & + & + & - & + & + & -1 & - & + & - & - & - & - & - & + & - & -1 & + & -1 & -1 & + & -1 & + & -1 & + & + & + & + & + & - & - & + & + & - & - & & \\
\hline 47 & & + & + & - & + & + & - & - & + & - & - & - & - & & + & - & + & + & -1 & - & + & - & - & + & + & + & + & +1 & + & - & - & + & + & - & - & & \\
\hline
\end{tabular}




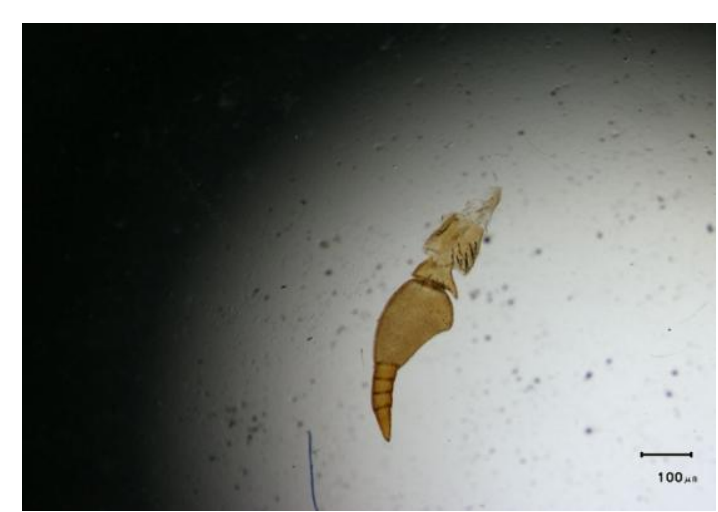

Plate 1: Sample Sh-T17 antenna: Type I

Hybomitra mendica

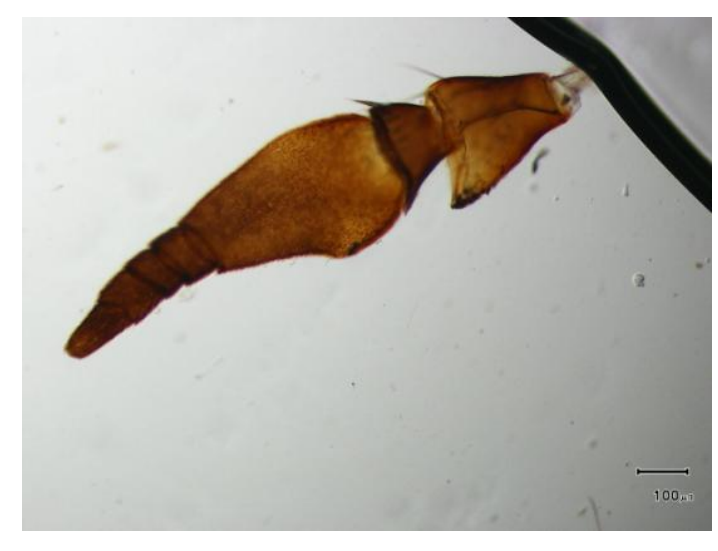

Plate 3: Sample Sh-T40 antenna: Type III

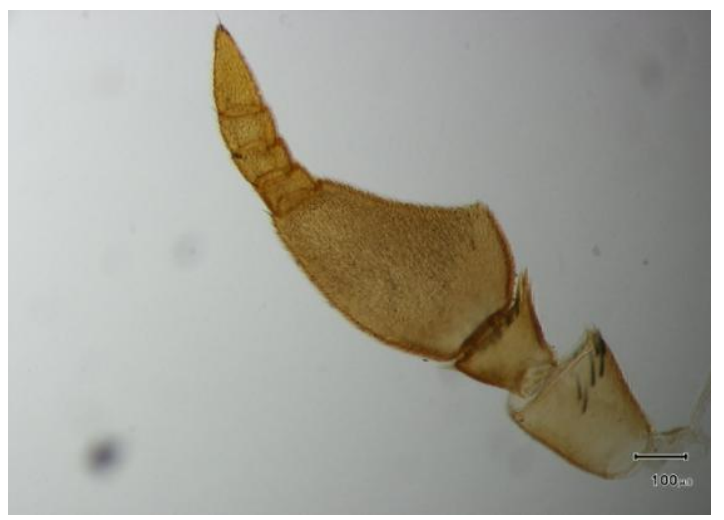

Plate 2: Sample Sh-T46 antenna: Type II

Tabanus leleani

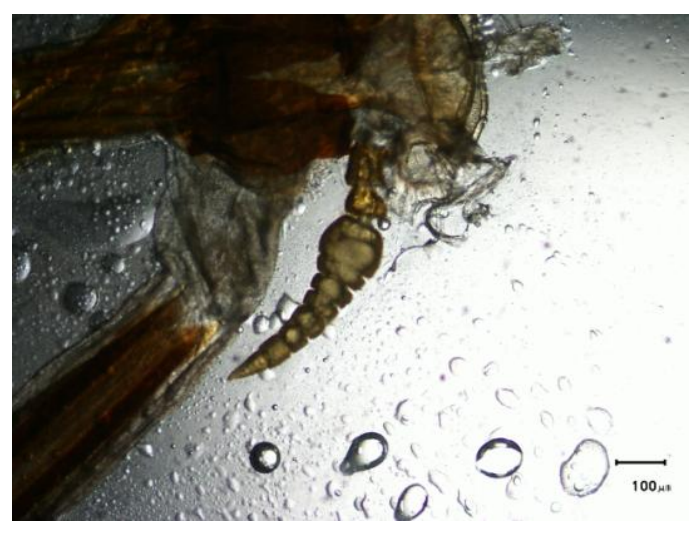

Plate 4: Sample Sh-T38 antenna: Type IV

Pangonia (Philoliche) spp.

Atylotus pulchellus

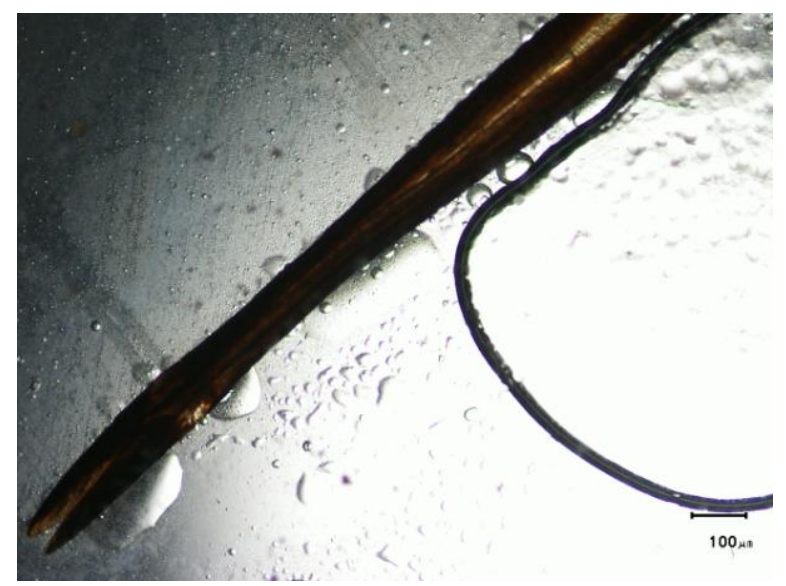

Plate 5: Sample Sh-T38 Mouthparts (proboscis):

Pangonia (Philoliche) spp. 


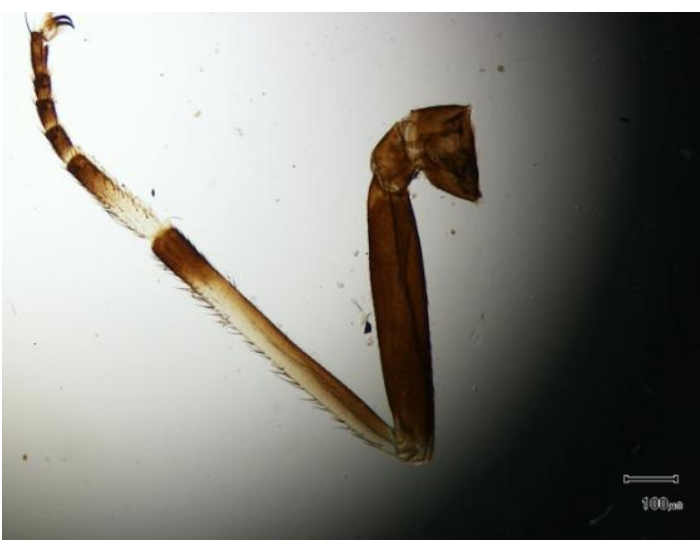

Plate 6: Sample Sh-T44 Hind tibia

Lack of apical spine on hind tibia

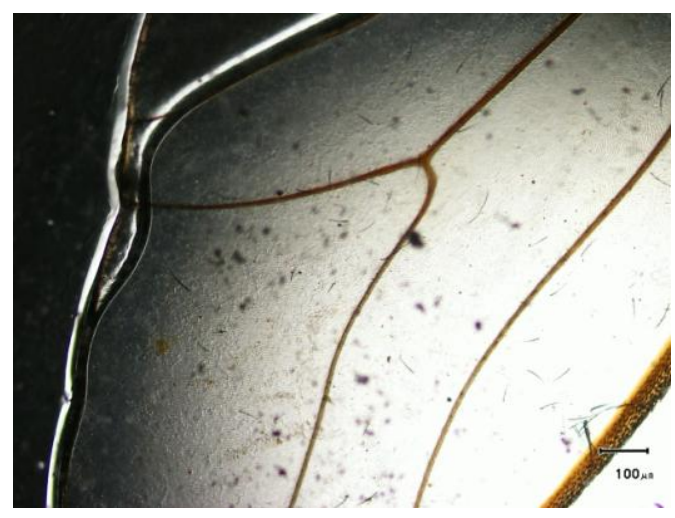

Plate 8: Sample Sh-T13 Wing: Type I

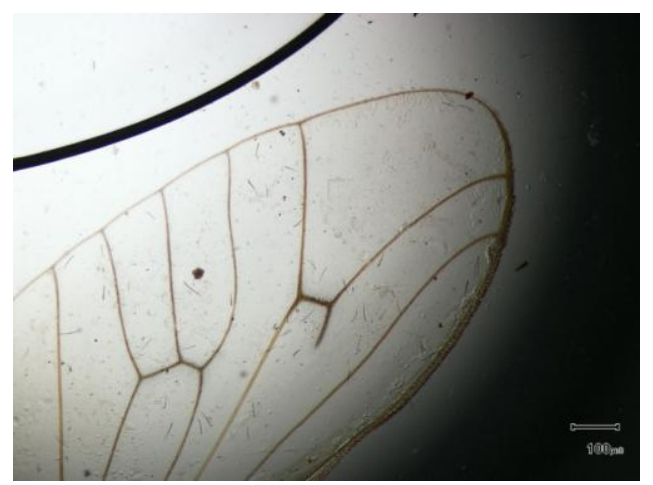

Plate 10: Sample Sh-T44 Wing: Type III

Big R4 appendix

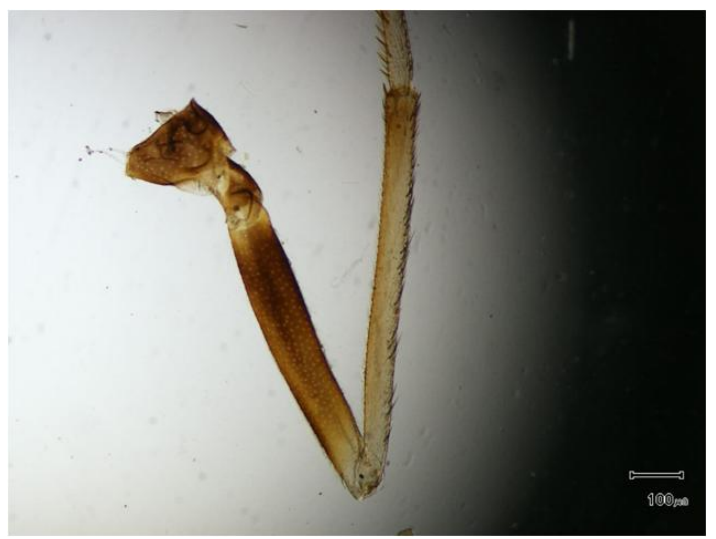

Plate 7: Sample Sh-T37 Hind tibia

Presence of spine on hind tibia

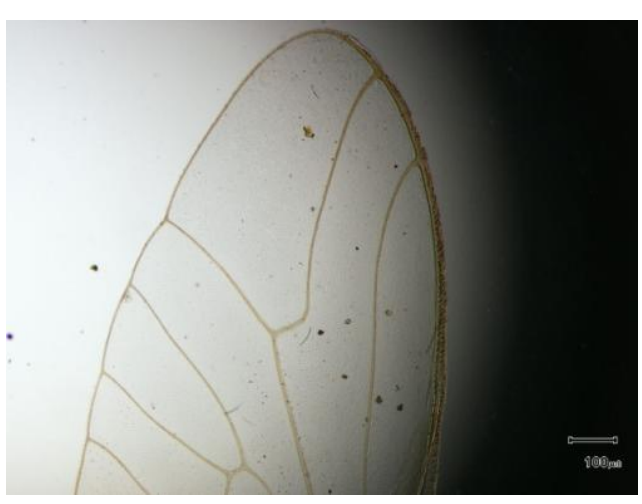

Plate 9: Sample Sh-T37 Wing: Type II

Fused R2 \& R3 (PC1, PC2 \& PC3; R4 without appendix)

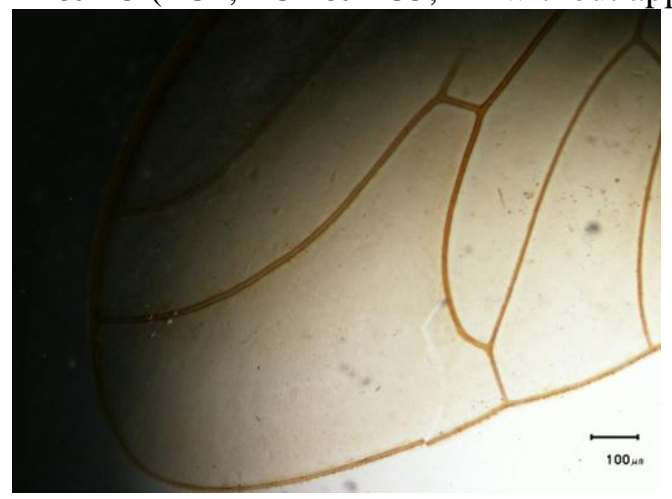

Plate 11: Sample Sh-T38 Wing: Type IV 


\section{DISCUSSION AND CONCLUSION}

Various species belong to Tabanidae family are known vectors and responsible for transmission of more than 80 viral, bacterial and protozoan diseases. Among them trypanosomosis, loa loa, anthrax are prevalent, they are responsible for economical loss in dairy industry as their easy targets are domestic cattle across the rural belts of several states in India [23].

There are an estimated 4,300 species of horse and deer flies in the world. More than 20 different species of tabanids have been shown experimentally to transmit $T$. evansi [24]. Furthermore, surveys of tabanids in the various tropical areas have shown a definite correlation between the seasonal outbreaks of $T$. evansi infections and the increase in number of tabanids during the rains [25], [26]. Thus, rainfall, suitable moisture-retaining clay soil and surface water pools also support the development of suitable camel browsing conditions, where Acacia senegal shrubs grow in abundance. Such conditions are applied to our study area; Al-Showak, which is a focal point for Camel Pastoralists in Butana area. Being a collection point, it becomes an important Camel market in the region [27], [28]. Since this study confirmed the presence of tabanids species; the known vector for $T$. evansi infection in Camles, the obtained results will be useful for the control measures of Camel trypanosomosis in the area in particular, and in the whole country in general. The prevalence of some Tabanus spp. all year round ensures that transmission of the parasite occurs wherever reservoir hosts, vectors and susceptible hosts co-exist. This finding may explain the sporadic occurrence of the disease during the dry season and outbreaks during the rainy season [26]. However, the efficiency of the different flies to transmit $T$. evansi appears to vary in different geographic conditions and is also dependent on the interval between two successive feeds and intensity of the fly challenge [24].

Since tabanids are strong fliers and readily disperse several kilometres in short-term flights with unchanged local population as shown previously [1], possible similar tabanids species may be exist in the nearby districts in Eastern Sudan where there are large Camels herds.

Similar to other blood-sucking insects such as mosquitoes for example, female horse flies use both chemical and visual cues to locate hosts. Carbon dioxide expelled by warm-blooded animals provides a long-range cue to attract flies from a distance, while visual cues such as motion, size, shape and dark color function to attract horse flies from shorter distances. This why we have used dark sheets in collecting tabanids flies during this study.

Taxonomic descriptions of each tabanid species is carried out following classification scheme of Berger and Thompson, 1981. The two ways to differentiate between Horse flies and deer flies is to look at their overall size and their wings. Horse flies tend to be much larger with a stouter body and a very large head with very large eyes. Their wings are usually clear or cloudy whereas deer flies have dark bands or spots across their wings. Tabanus species range from medium -sized to very large, robust insect. Most have a body length $(5-25 \mathrm{~mm})$, with the longest having of $60 \mathrm{~mm}$ [29]. Mostly, all of the collected samples have body length size ranges from $8 \mathrm{~mm}$ to $17 \mathrm{~mm}$, with antennae shorter than head with a thick base. The wings are clear or uniformly cloudy. It is suggested that all of the collected tabanids don't bite humans when considering their feeding behavior, since all were collected from areas not inhibited by humans.

In the adult tabanids females the eyes are widely separated but in males they are almost touching; they are often patterned and brightly colored in life but appear dull in preserved specimens. In the current study this feature is not observed due to the preservation method. Previous studies have described some identification features to distinguish between the different families members. For example, the Tabanidae are lacking ocelli and have no spurs on the tips of their hind tibia. In the pangoniiae, ocelli are present and the antennal flagellum usually has eight annuli. In the Chrysopsinae, the antennal flagellum has a basal plate and the flagellum has four annuli. Females have a shining callus on the front [30] .The Adersiinae have a divided tergite on the ninth abdominal segment [7]. 
However, the observed shape of antennae in the collected flies' samples looks very similar to the previously reported ones. The terminal segment of the antennae is pointed and is annulated, this annulations which is also known as flagellomeres are of two types. The number of flagellomeres in apical part of flagellum is also found to be key character on the basis of which several genera of Tabanidae can be distinguished from each other [23]. However, during this study all of the collected samples have 5 flagellomeres on their flagellum with only one exception in sample (Sh-T38) which has instead 8 flagellomeres. This sample also has got well developed ocelli on the head, proboscis longer than the head, appendix on the R4 vein of the wing and has large spurs on the hind tibiae. Therefore this sample belongs to Subfamily: Pangoniinae and tribe: Philolichini and can be classified as belonging to the genus Philoliche Wiedemann, 1828 Pangonia species. However, some samples have flagellum with large basal plate and 4 annuli; wing hyaline or dusty; basicosta in wing with strong setae. Therefore, these samples belong to Subfamily: Tabaninae and tribe: Tabanini.

Another study has described characteristic features for the mouthparts; that the mouth parts of tabanids females are of the usual Dipteran form and consist of bundle of six chitinous stylets that together with a fold of the flesh labium, form the proboscis, when the insect lands on an animal it grips the surface with it clawed feat, the labium, is retracted, the head is thrust downwards and the stylets slice in to the flesh. Some of these have sawing edges and muscles can move them from side-to-side to enlarge the wound. Saliva containing anticoagulant is injected in to the wound to prevent clotting [31].

A previous description of the tabanids legs is also reported. The tips of the legs have shown to have two lobes on the pulvilii and a central lobe or empodium in addition to two claws that enable them to grip surfaces [32]. Legs are composed of several parts i.e. coxae, femora, tibiae and tarsi. Presence of white bands on mid and hind tibiae and coloration of fore-femora and tarsi bear important characters [23].

As previously described [33], [34], the wing of most of the collected samples is smoky or hyaline and the biscosta bears strong setae as represented by samples Sh-T13, Sh-T37, Sh-T44 and Sh-T38 in Plates 8, 9, 10 and 11; respectively. However, most of the collected samples have shown wings structure resembles that described recently in India for Tabanus striatus [33]. The wing pattern based on the presence of an appendix in R4 vein is reported previously from Saudia Arabia [35] in a female of Atylotus argestis (Wiedemann). During the current study, this pattern is observed in samples Sh-T38 and Sh-T44 as illustrated in Plates 11 and 10; respectively. This tabanid species was described earlier [36] and it is distributed in Afrotropical, Palaearctic and Oriental regions of the World [35]. There is a small humeral sclerite (basicosta) on the beginning of costal vein on many of the collected samples. The presence of pubescence on the basicosta is an important taxonomic feature.

According to the schematic description of the antenna of female tabanids that described previously [37], four types of antennae were observed in the collected samples from Al-Showak district. Type I is observed in sample Sh-T17 (Plate 1) that resembles the tabanid species of the genus Philipomyia. While, type II is observed in sample Sh-T46 (Plate 2) that resembles the tabanid species of the genus Dasyrhamphis. Sh-T46 has appendix on R4 vein of the wing. On the other hand, other samples have different shape on the junction of R4 and R5, and others have appendix on R4 vein of the wing, these two features exclude these samples from the genus Philipomyia. Moreover, sample Sh-T44 has appendix on R4 vein of the wing, a feature exclude this sample from the genus Dasyrhamphis. Therefore type III is observed in sample Sh-T40 (Plate 3). Type IV in only observed in sample Sh-T38 (Plate 4) that resembles the tabanid species of the genus Pangonius. Since there is no evidence of any record of the presence of these two genra in the Tabanidae fauna of the Sudan [38], [39], this is the first report of them.

Overall, according to the schematic description of the wings and antennae of tabanids from Jordan that described previously [40], five species have been identified; these are: [1] Tabanus autumnalis (Szilády 1914) represented by sample Sh-T13; [2] Tabanus leleani (Austen 1920) represented by the samples ShT15, Sh-T24, Sh-T31, Sh-T34, Sh-T36, Sh-T37, Sh-T41, Sh-T46 and Sh-T47; [3] Atylotus pulchellus (Loew 1858) represented by the samples Sh-T40, Sh-T42, Sh-T44 and Sh-T45; [4] Hybomitra mendica 
(Villeneuve 1912) represented by the samples Sh-T16, Sh-T17 and Sh-T25; [5] Pangonius (Philoliche) spp. All together, the tabanidae of Gedaref exhibit highest species richness particularly from Al-Showak district.

A morphological identification key for horse flies from the Eastern region of the Sudan has been created for the first time and can be used as taxonomical tool.

Generally during this study, more tabanids flies were collected during the wet $(171 ; 52.29 \%)$ than the dry season $(156 ; 47.71 \%)$. These findings were reported in a similar study from Nigeria [41]. However, the abundance of the male flies is more during the wet season $(23.39 \%)$ than the dry season $(5.13 \%)$. On the other hand, the abundance of the female tabanids is more during the dry season $(94.87 \%)$ than the wet season $(76.61 \%)$. One possible reason is that male density increases in the wet season for the purpose of mating. Altogether, the female density is more or less similar during both seasons. The widespread of tabanids in the study area suggests that they could be playing a greater role in disease transmissions than previously thought. Moreover, horse flies are an annoyance to livestock, as well as humans. Heavy biting rates can lead to weight loss in beef cattle, reduced milk yield in dairy cattle and hide damage from the fly's puncture wounds. Very interesting that during this study we observed the presence of dragonflies in the samples collection site, and since it is known that deer flies natural predators include dragonflies we expect that some of the available tabanids flies are deer flies, although this is confirmed in the current study.

The present study revealed the presence of 5 species of Tabanidae namely; Tabanus autumnalis (Szilády 1914); Tabanus leleani (Austen 1920); Atylotus pulchellus (Loew 1858); Hybomitra mendica (Villeneuve 1912) and Philoliche sp. to be reported for the first time from the Showak district in the state of Gedaref. Four groups of samples were identified to the species level, while one sample which represents the subfamily Pangoniinae was identified to the genus level only.

\section{Acknowledgments}

The help of the staff of the Veterinary Research Laboratory in Al-Showak is gratefully acknowledged. This work is supported by a research grant from the Directorate for Scientific Research and Cultural Relations, University of Khartoum, Republic of the Sudan.

\section{References}

[1]. B. A. Mullens, Horse flies and deer flies (Tabanidae), in Mullen G, Durden L (eds.), Medical and Veterinary Entomology, (Academic Press, London, 2002), 263-77.

[2]. M. Chvála, L. Lyneborg and J. Moucha, Horse Flies of Europe (Diptera, Tabanidae), (Entomological Society of Copenhagen, sole agent: E. W. Classey, Hampton, Middlesex, Eng., 1972), ISBN 978-0900848-57-5.

[3]. J. Moucha, Horse-flies (Diptera: Tabanidae) of the World: Synoptic Catalogue. (Národní muzeum Přírodovědecké museum, 1976).

[4]. J. F. Burger. (1995). Catalogue of Tabanidae (Diptera) of North America north of Mexico. Contrib Entomol Int., 1, 1995, 1-100.

[5]. S. I. Morita, K. M. Bayless, D. K. Yeates and B. M. Wiegmann. "Molecular phylogeny of the horse flies: a framework for renewing tabanid taxonomy". Systematic Entomology, 41(1), 2015, 56-72.

[6]. G. B. Fairchild. Climate and the phylogeny and distribution of Tabanidae. Bull Entomol Soc Am. 15, 1969, 7-11.

[7]. I. M. Mackerras. The classification and distribution of Tabanidae (Diptera). I. General review. Aust J Zool., 2, 1954, 431-54.

[8]. R. W. Crosskey and B. F. Crosskey. The Horse-Flies (Diptera: Tabanidae) of Nigeria and British Camerons. Transactions of the Entomological Society of London, 106 (8), 1955, 341-374. 
[9]. W. L. Krinsky. Animal disease agents transmitted by horse flies and deer flies (Diptera: Tabanidae). $J$ Med Entomol., 13(3), 1976, 225-75.

[10]. M. Chvála and J. Ježek. (1997). Diptera Tabanidae, Horse Flies, in ANDERS N. (ed.), The aquatic Insects of North Europe 2, (Apollo Books, Stenstrup, 1997), 295-309.

[11]. A. T. M. Barros. Seasonality and relative abundance of Tabanidae (Diptera) captured on horses in the Pantanal, Brazil. Memórias do Instituto Oswaldo Cruz, Rio de Janeiro, 96 (7), 2001, 917-923.

[12]. R. L. M. Ferreira, A. L. Henriques and J. A. Rafael. Activity of Tabanids (Insecta: Diptera: Tabanidae) Attacking the Reptiles Caiman crocodilus (L.) (Alligatoridae) and Eunectes murinus (L.) (Boidae), in the Central Amazon, Brazil. Memórias do Instituto Oswaldo Cruz, 97(1), 2002, 133-136.

[13]. S. A. Allan and J. G. Stoffolano. The effects of hue and intensity on visual attraction of adult Tabanus nigrovittatus (Diptera: Tabanidae). J. Med. Entomol. 23, 1986a, 83 - 91.

[14]. S. A. Allan and J. G. Stoffolano. Effects of background contrast on visual attraction and orientation of Tabanus nigrovittatus (Diptera: Tabanidae). Environ. Entomol. 15, 1986b, 689 - 694.

[15]. G. K. Bracken, W. M. Hanec and A. J. Thorsteinson. The orientation behavior of horseflies and deerflies (Tabanidae: Diptera). II. The role of some visual factors in the attractiveness of decoy silhouettes. Can. J. Zool. 40, 1962, $685-695$.

[16]. A. C. Nilssen. Effect of 1-octen-3-ol in field trapping Aedes spp.(Diptera, Culicidae) and Hybomitra spp.(Diptera, Tabanidae) in subarctic Norway. J. Appl.Entomol. 122, 1998, 465-468.

[17]. M. Hall and R. Wall, Biting flies: their role in the mechanical transmission of trypanosomes to livestock and methods for their control, in I. Maudlin, P. H. Holmes, and M.A. Miles (eds.), The trypanosomiases (CAB Publishing 33, 2004), 573-583.

[18]. M. Okech and A. Hassan. The origin of phenolic tsetse attractants from host urine studies on the pro-attractants and microbes involved. Insect Sci. Appl.11, 1990, 363-368.

[19]. L. C. Madubunyi, A. Hassanali, W. Ouma, D. Nyarango and J. Kabii. Chemoecological role of mammalian urine in host location by tsetse, Glossina spp. (Diptera: Glossinidae). J Chem Ecol. 22(6), 1996,1187-99.

[20]. S. Krcmar, L. J. Hribar and M. Kopi. Response of Tabanidae (Diptera) to natural and synthetic olfactory attractants. J Vector Ecol. 30(1), 2005, 133-6.

[21]. S. Mihok, D. A. Carlson and P. N. Ndegwa. Tsetse and other biting fly responses to Nzi traps baited with octenol, phenols and acetone. Med Vet Entomol. 21(1), 2007, 70-84.

[22]. M. Aboud, A. Makhawi, A. Verardi, F. El Raba'a, D. E. Elnaiem and H. Townson. A genotypically distinct, melanic variant of Anopheles arabiensis in Sudan is associated with arid environments. Malar J. 13, 2014, 492.

[23]. A. Maity, A. Naskar, E. Mukhopadhyay, S. Hazra, J. Sengupta, S. Ghosh and D. Banerjee. Taxonomic studies on Tabanidae (Insecta: Diptera) from Himachal Pradesh, India. International Journal of Fauna and Biological Studies. 2 (4), 2015, 43-52.

[24]. A. G. Luckins. Epidemiology of Surra: Unanswered Questions. J. Protozool. Res. 8, 1998, 106-119.

[25]. M. M. Mahmoud and A. R. Gray. Trypanosomosis due to Trypanosoma evansi (Steel, 1885)

Balbiani, 1888. A review of recent research. Top. Anim. Hlth. Prod. 12, 1980, 35-47.

[26]. Z. K. Njiru, O. Bett, I. M. Ole-Mapeny, J. B. Githiori and J. M. Ndung'u. Trypanosomosis and helminthosis in camels: comparison of ranch and traditional camel management systems in Kenya. $J$. Camel Practice Research 55, 2002, 67-71.

[27]. N. O. M. Ali, H. Croof and H. S. Abdalla. Molecular Diagnosis of Trypanosoma evansi Infection in Dromedary Camels from Eastern and Western regions of the Sudan. Emirates Journal of Food and Agriculture 23(4), 2011, 320-329.

[28]. H. I. Croof H. S. Abdalla and N. O. M. Ali. Assessment of Trypanosoma evansi Infection in Camels herd from Gedariff and Kordofan states. University of Khartoum Journal of Veterinary Medicine and Animal Production. 3 (1), 2012, 3-27.

[29]. G. C. Cook and A. Zumla, Manson's Tropical Diseases (Elsevier. p. 1752. ISBN 1-4160-4470-1, 2009) 
[30]. D. H. Colless and D. K. McAlpine, Chapter 39: Diptera, in CSIRO (Ed.), The Insects of Australia. Volume 2. (2 ed.), (CSIRO, 1991), 754-755.

[31]. M. Kazimírová, M. Šulanová, M. Kozánek, P. Takáč, M. Labuda and P. A. Nuttall. "Identification of anticoagulant activities in salivary gland extracts of four horsefly species (Diptera, Tabanidae)". Haemostasis 31, 2001, 294-305.

[32]. J. E. Chainey, Horse-flies, deer-flies and clegs (Tabanidae), in R.P. Lane \& R.W. Crosskey (Eds.), Medical Insects and Arachnids, (Chapman and Hall, London, 1993), 310-332.

[33]. K. Chandra, S. Halder, A. Raha, P. Parui and D. Banerjee. Tabanid flies (Insecta: Diptera) from Chhattisgarh, India. Journal of Threatened Taxa, 7(10), 2015, 7720-7725.

[34]. H. S. Jasim, A. J. Sabr and A. S. Daoud. External Morphological Study of Tabanus autumnalis L. 1761, (Diptera: Tabanidae) in Iraq. Ibn Al-Haitham J. for Pure \& Appl. Sci. 28 (3), 2015, 1-6.

[35]. H. M. Al Dhafer, H. A. Dawah and M. A. Abdullah. Tabanidae (Diptera) of Saudi Arabia. Saudi Journal of Biological Sciences, 16, 2009, 77-83.

[36]. M. A. Amoudi. New records of Tabanidae (Diptera) from southwest Saudi Arabia with some aspects of their distributions and biological information. Journal of Biological Science Research 20, 1989, 115-127.

[37]. S. Krcmar, D. K. Hackenberger and B. K. Hackenberger. Key to the horse flies fauna of Croatia (Diptera, Tabanidae). Periodicum Biologorum, 113, Suppl 2, 2011, 1-61

[38]. A. I. Yagi. A contribution to the knowledge of the tabanidae of the Sudan, Ph. D. Thesis, Faculty of Agriculture, University of Khartoum, 1968.

[39]. M. M. Mohamed-Ahmed and S. Mihok. A lighting of Tabanidae and muscids on natural and simulated hosts in the Sudan. Bulletin of Entomological Research, 99, 2009, 561 - 57.

[40]. H. Al-Talafha, Z. S. Amr, M. A. Baker and A. K. Bader. Horseflies of Jordan. Med Vet Entomol. 18(2), 2004, 208-11.

[41]. A. B. Ahmed, S. N. Okiwelu and S. M. Samdi. Species Diversity, Abundance and Seasonal Occurrence of Some Biting Flies in Southern Kaduna, Nigeria. African Journal of Biomedical Research, 8, 2005, 113 - 118 . 